\title{
Prediksi Bencana Alam di Kota Semarang Menggunakan Algoritma Markov Chains
}

\author{
Nurtriana Hidayati ${ }^{1)}$, Prind Triajeng Pungkasanti ${ }^{2}$, Nur Wakhidah ${ }^{3)}$ \\ 1)2)3) Prodi Sistem Informasi, Fakultas Teknologi Informasi dan Komunikasi, Universitas \\ Semarang \\ Jl. Soekarno Hatta - Semarang \\ 1) anna@usm.ac.id \\ 2) prind@usm.ac.id \\ 3) ida@usm.ac.id
}

\begin{abstract}
Abstrak
Bencana alam bukan merupakan hal baru di Indonesian khususnya kota semarang. Data tersebut dapat di lihat pada Badan Penanggulangan Bencana Daerah (BPBD). Data bencana alam yang digunakan sebagai data penelitian diambil dari tahun 2013 hingga 2020 dengan jenis bencana alam berupa banjir, banjir rob, puting beliung, tanah longsor, rumah roboh, pohon tumbang dan kebakaran yang semuanya perlu kita waspadai dan ditanggulangi untuk memperkecil kerugian bagi masyarakat. Prediksi merupakan hal yang dipakai setiap kalangan untuk mengetahui seberapa besar hal yang mungkin terjadi dimasa yang akan datang. Markov Chains adalah metode untuk menghasilkan nilai kemungkinan terhadap sesuatu dengan perhitungan probabilitas. Markov chains disini melakukan prediksi dengan nilai matrik terhadap 7 bencana alam yang terjadi di kota Semang dengan hasil prediksi di tahun 2020 adalah banjir $35 \%$, rob banjir $0 \%$, tanah longsor $22 \%$, puting beliung $3 \%$, rumah roboh $2 \%$, kebakaran $30 \%$ dan pohon tumbang $8 \%$. Sedangkan di tahun 2021 prosentase prediksi banjir $22 \%$, rob banjir $3 \%$, tanah longsor $22 \%$, puting beliung $2 \%$, rumah roboh $8 \%$, kebakaran $33 \%$ dan pohon tumbang $9 \%$.
\end{abstract}

Kata kunci: Prediksi, Algoritma Markov Chains, Bencana Alam

\begin{abstract}
Natural disasters are not a new thing in Indonesia, especially in Semarang. The data can be seen at the Regional Disaster Management Agency (BPBD). Natural disaster data used as research data taken from 2013 to 2020 with the types of natural disasters in the form of floods, tornadoes, landslides, collapsed houses, fallen trees and fires that all of which we need to be aware of and overcome to minimize losses for the community. Prediction is something that everyone uses to find out how big things might happen in the future. Markov Chains is a method for generating a probability value against something with a probability calculation. Markov chains here make predictions with a matrix value of 7 natural disasters that occur in Semarang with prediction results in 2020 are floods $35 \%$, flood rob $0 \%$, landslides $22 \%$, twisters $3 \%$, houses collapsed $2 \%$, fires $30 \%$ and trees fell $8 \%$. While in 2021 the percentage of floods prediction is $22 \%$, flood rob $3 \%$, landslides $22 \%$, tornadoes $2 \%$, houses collapsed $8 \%$, fires $33 \%$ and trees fell $9 \%$.
\end{abstract}

Keywords: Prediction, Markov Chains Algorithm, Natural Disasters

\section{PENDAHULUAN}

Bencana alam muncul sebagai reaksi perubahan kondisi bumi baik secara alami maupun kesalahan atau ulah manusia (human error) yang kadang datang tanpa diketahui maupun bisa diprediksi sehingga mengakibatkan gempa bumi, tsunami, gunung meletus, banjir, kekeringan 
akibat kemarau panjang, angin topan, dan tanah longsor. Terjadinya bencana tersebut membuat kerugian yang sangat besar, baik dari segi materiil maupun korban manusia [1]. Semarang adalah salah satu kota di Jawa Tengah, merupakan daerah yang secara aspek geografis, klimatologis dan demografis, negara Republik Indonesia terletak di daerah rawan bencana. Jawa tengan merupakan wilayah yang intensitas bencana alam juga sering terjadi khususnya wilayah kota semarang. Hal tersebut dapat di lihat dari data Badan Penanggulangan Bencana Daerah (BPBD) Jawa Tengah terdapat 7 (tujuh) jenis kejadian bencana meliputi banjir, rob banjir, tanah longsor, angin puting beliung, kebakaran, rumah roboh, dan pohon tumbang [2], [3]. Jika bencana telah terjadi tanpa adanya peringatan maka banyak sekali kerugian ataupun korban yang berjatuhan. Hal tersebut menjadikan permasalahan yang perlu untuk diselesaikan, setidaknya kita mampu memprediksikannya agar kita bisa melakukan penanggulangannya atau antisipasi dini agar kerugian maupun korban tidak terjadi. Melihat tersebut diperlukan suatu formula atau pola prediksi sebagai pengetahuan baru untuk mengurangi atau setidaknya mencegah bencana alam sejak dini [3].

Berdasarkan data BPBD dalam situs websitenya memperlihatkan perubahan yang segnifikan dari jumlah bencara yang ada di tahun 2013 sampai 2020 [2]. Dimana nilai tersebut cenderung mengalami kenaikan. Melihat hal maka harus ada sebuah terobosan untuk menanggulangi atau menekan tingkat kejadian bencana agar masyarakat lebih merasa aman dalam kehidupannya. Untuk itu perlu dilakukan prediksi kejadian bencana alam pada kota semarang, dengan memanfaatkan metode data mining.

Markov Chains merupakan algoritma yang menghitung berdasarkan nilai probabilitas kejadian terhadap kejadian sebelumnya melalui perkiraan nilai transisi yang diamati [4]. Melihat data BPBD dari tahun-tahun sebelumnya menjadikan algaritma markov chains memiliki kecocokan dari konsep probabilitas. Riwayat kejadian pada BPBD akan dibandingkan berdasarkan nilai matriknya untuk memprediksikan bencana alam di tahun yang akan datang, dalam nilai prosentasi. Dengan nilai prediksi tersebut akan memberikan kontribusi pihak terkait dalam stategi penanggulangan bencana secara lebih dini sehingga mengurangi adanya kerugian maupun korban.

\section{TINJAUAN PUSTAKA}

Rantai Markov (Markov Chains) adalah suatu teknik matematika yang biasa digunakan untuk melakukan pemodelan (modelling) bermacam-macam sistem dan proses bisnis. Model Rantai Markov ditemukan oleh seorang ahli Rusia yang bernama A.A. Markov pada tahun 1906, yaitu: "Untuk setiap waktu t, ketika kejadian adalah Kt dan seluruh kejadian sebelumnya adalah Kt(j), $\ldots, \mathrm{Kt}(\mathrm{j}-\mathrm{n})$ yang terjadi dari proses yang diketahui, probabilitas seluruh kejadian yang akan datang $\mathrm{Kt}(\mathrm{j})$ hanya bergantung pada kejadian $\mathrm{Kt}(\mathrm{j}-1)$ dan tidak bergantung pada kejadian-kejadian sebelumnya yaitu $\mathrm{Kt}(\mathrm{j}-2), \mathrm{Kt}(\mathrm{j}-3), \ldots, \mathrm{Kt}(\mathrm{j}-\mathrm{n})$." Gambaran mengenai rantai Markov ini kemudian dituangkan dalam Gambar 1 dimana gerakan-gerakan dari beberapa variabel di masa yang akan datang bisa diprediksi berdasarkan gerakan-gerakan variabel tersebut pada masa lalu. Kt4 dipengaruhi oleh kejadian Kt3, Kt3 dipengaruhi oleh kejadian Kt2 dan demikian seterusnya dimana perubahan ini terjadi karena peranan probabilitas transisi (transition probability). Kejadian Kt2 misalnya, tidak akan mempengaruhi kejadian Kt4 [5], [6]. 


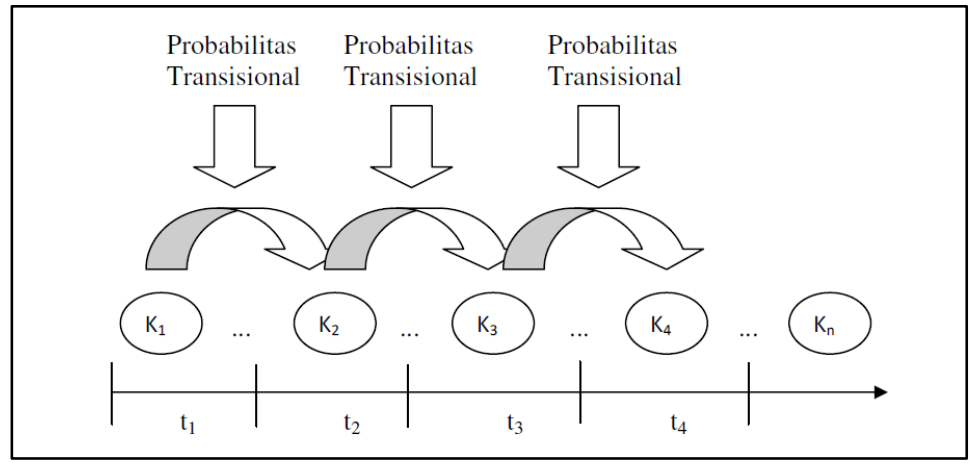

Gambar 1. Peristiwa dalam rantai Markov

Kejadian-kejadian di atas sifatnya berantai. Oleh karena itu, teori ini dikenal dengan nama Rantai Markov. Dengan demikian, Rantai Markov akan menjelaskan gerakan-gerakan beberapa variabel dalam satu periode waktu di masa yang akan datang berdasarkan pada gerakan-gerakan variabel tersebut di masa kini. Secara matematis dapat ditulis [6]:

$K t(j)=P x \operatorname{Kt}(j-1)$

Dimana :

$\mathrm{Kt}(\mathrm{j}) \quad=$ peluang kejadian pada $\mathrm{t}(\mathrm{j})$

$\mathrm{P} \quad=$ Probabilitas Transisional

$\mathrm{t}(\mathrm{j}) \quad=$ waktu ke-j

Peluang kejadian $\mathrm{Kt}(\mathrm{j})$ dinyatakan ke dalam bentuk vektor sehingga jumlah seluruh selnya akan selalu $100 \%$.

\section{Probabilitas Absolut dan Transisi}

Dengan diketahui \{aj0\} dan P dari sebuah rantai Markov, probabilitas absolut dari sistem tersebut setelah sejumlah transisi tertentu ditentukan sebagai berikut. Anggaplah \{aj0\} adalah probabilitas absolut dari sistem tersebut setelah $n$ transisi, yaitu pada saat tn. Ekspresi umum dari $\{$ aj0 $\}$ dalam bentuk \{aj0\} dan P dapat ditemukan sebagai berikut [5], [7].

$a_{j}^{(1)}=a_{1}^{(0)} P_{1 j}+a_{2}^{(0)} P_{2 j}+a_{3}^{(0)} P_{3 j}+\cdots=\sum a_{i}^{(0)} P_{i j}$

Juga

$a_{j}^{(2)}=\sum_{i} a_{i}^{(1)} P_{i j}=\sum_{i}\left(\sum_{k} a_{k}^{(0)} P_{k i}\right) P_{i j}=\sum_{k} a_{k}^{(0)}\left(\sum_{i} P_{k i} P_{i j}\right)=\sum_{k} a_{k}^{(0)} P_{k j}^{(2)}$

dimana adalah probabilitas transisi dua langkah atau order kedua (two step atau second-order transition probability), yaitu probabilitas untuk bergerak dari keadaan $\mathrm{k}$ kekeadaan $\mathrm{j}$ dalam tepat dua transisi. Demikian pula dapat diperlihatkan berdasarkan induksi bahwa:

$a_{j}^{(n)}=\sum_{i} a_{i}^{(0)}\left(\sum_{k} P_{i k}^{(n-1)} P_{k j}\right)=\sum_{i} a_{i}^{(0)} P_{i j}^{(n)}$

dimana $P_{i j}^{(n)}$ adalah probabilitas transisi n langkah atau order $\mathrm{n}$ dengan diketahui rumus rekursif.

$P_{i j}^{(n)}=\sum_{k} P_{i k}^{(n-1)} P_{k j}$

Secara umum, untuk semua $i$ dan $j$ 


$$
P_{i j}^{(n)}=\sum_{k} P_{i k}^{(n-m)} P_{k j}^{(m)}, 0<m<n
$$

Persamaan-persamaan ini dikenal sebagai persamaan Chapman-Kolmogorov. Elemen-elemen dan matriks transisi yang lebih tinggi $\|\mathrm{Pij}(\mathrm{n})\|$ dapat diperoleh secara langsung dengan perkalian matriks. Jadi

$\left\|P_{i j}^{(2)}\right\|=\left\|P_{i j}\right\|\left\|P_{i j}\right\|=P^{2}$
$\left\|P_{i j}^{(3)}\right\|=\left\|P_{i j}^{2}\right\|\left\|P_{i j}\right\|=P^{3}$

dan secara umum,

$\left\|P_{i j}^{(n)}\right\|=P^{n-1} P=P^{n}$

\section{METODE PENELITIAN}

Tahapan dalam penelitian untuk memprediksi bencana alam pada kota Semarang melalui beberapa proses :

a. Pengumpulan Data

Data penelitian berasal dari laporan kejadian bencana yang berada pada situs BPBD yang terekam dari tahun 2012 sampai 2020, namun dalam penelitian ini hanya diambil dari tahun 2013 hingga 2020. Data tersebut berupa jumlah kejadian bencana pada tiap tahun di kota Semarang.

b. Menentukan Data Set sebagai Data Training

Melihat dari data yang kompleks dimana tiap kecamatan memiliki beranekaragam kejadian, maka dilakukan pengelompokan dengan menghitung jumlah kejadian tiap bencana pada tiap tahunnya. Dari data 2013 sampai 2020 akan dibagi menjadi 2 bagian yaitu data training yang berasal dari tahun 2013 sampai 2019 [8]. Sedangkan data tahun 2020 digunakan sebagai data testing atau data evaulasi hasil pediksi markov chains. Hasil data training kemudian dilakukan formulasi dengan algoritma markov chains.

c. Penghitungan Markov Chains

Data training di buat matrik kemudian dihitung menggunakan rumus rantai markov chains. Nilai yang didapat adalah berupa nilai persentase tiap kejadian bencana yang ada di kota Semarang.

d. Validasi

Tahapan validasi ini adalah dilakukan evaluasi hasil prediksi dengan data testing yang teah di tentukan sebelumnya. Hal ini untuk melihat nilai akurasi antara kenyataan dengan hasil prediksi.

Tahapan penelitian di atas digambarkan dalam bentuk diagram alir proses seperti yang terlihat pada gambar 2 di bawah ini. 


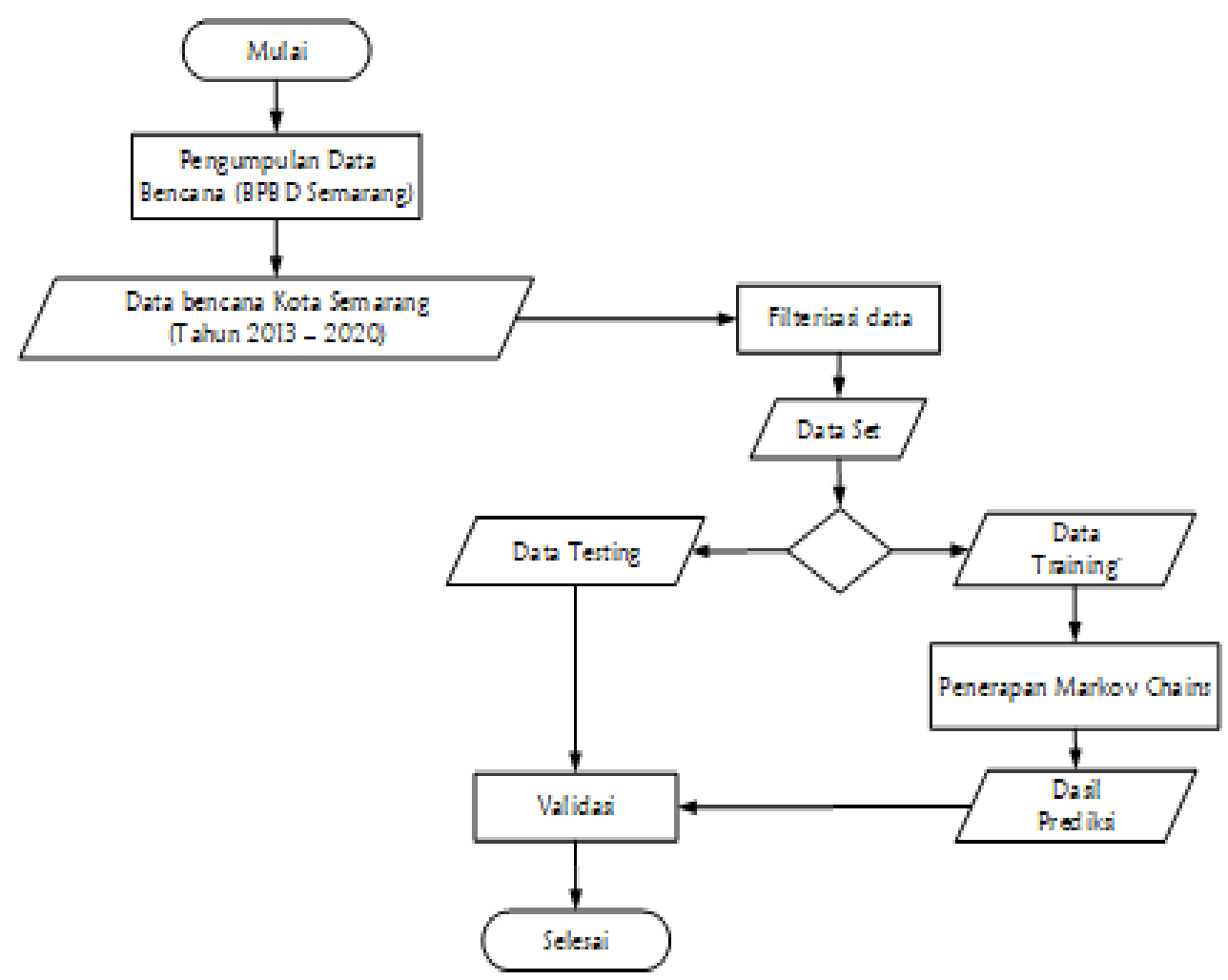

Gambar 2. Diagram alir tahapan penelitian

\section{PEMBAHASAN}

Tahap pengumpulan data terlihat pada tabel 1. Pada tabel 1 ditampilkan keseluruhan data ke 7 bencana kota Semarang dari tahun 2013 hingga 2020 yang berasal dari laporan BPBD melalui website resminya [9], [10]. Dimana tabel di bawah memperlihatkan jumlah bencana tiap tahunnya.

Tabel 1. Data bencana alam BPBD Kota Semarang tahun 2013-2020

\begin{tabular}{cccccccc}
\hline Tahun & Banjir & $\begin{array}{c}\text { Rob } \\
\text { Banjir }\end{array}$ & $\begin{array}{c}\text { Tanah } \\
\text { Longsor }\end{array}$ & $\begin{array}{c}\text { Puting } \\
\text { Belitung }\end{array}$ & $\begin{array}{c}\text { Rumah } \\
\text { Roboh }\end{array}$ & Kebakaran & $\begin{array}{c}\text { Pohon } \\
\text { Tumbang }\end{array}$ \\
\hline $\mathbf{2 0 1 3}$ & 69 & 0 & 44 & 6 & 4 & 60 & 16 \\
$\mathbf{2 0 1 4}$ & 26 & 0 & 123 & 5 & 20 & 57 & 6 \\
$\mathbf{2 0 1 5}$ & 48 & 0 & 30 & 0 & 11 & 84 & 12 \\
$\mathbf{2 0 1 6}$ & 30 & 0 & 52 & 1 & 14 & 44 & 11 \\
$\mathbf{2 0 1 7}$ & 36 & 0 & 82 & 5 & 31 & 69 & 45 \\
$\mathbf{2 0 1 8}$ & 34 & 38 & 87 & 1 & 47 & 103 & 36 \\
$\mathbf{2 0 1 9}$ & 19 & 4 & 89 & 21 & 53 & 108 & 61 \\
$\mathbf{2 0 2 0}$ & 21 & 0 & 124 & 4 & 22 & 25 & 11 \\
\hline
\end{tabular}

Data di atas memperlihatkan jumlah bencana yang terjadi tiap tahunnya dengan beberapa jenis bencana yaitu banjir (B), rob banjir (RB), tanah longsor (TL), puting beliung (PB), rumah roboh (RR), kebakaran (K), dan pohon tumbang (PT) di kota Semarang. Berdasarkan alur proses sebelumnya bahwa data 2013 - 2020 akan di bagi menjadi 2 jenis yaitu sebagai data training dan data testing. Data training diambil dari data kejadian daru tahun 2013 sampai 2019, kemudian di hitung total kejadian tiap tahunnya, sehingga terlihat pada tabel 2 berikut ini: 
Tabel 2. Data training

\begin{tabular}{ccccccccc}
\hline Tahun & B & RB & TL & PB & RR & K & PT & JUMLAH \\
\hline $\mathbf{2 0 1 3}$ & 69 & 0 & 44 & 6 & 4 & 60 & 16 & 199 \\
$\mathbf{2 0 1 4}$ & 26 & 0 & 123 & 5 & 20 & 57 & 6 & 237 \\
$\mathbf{2 0 1 5}$ & 48 & 0 & 30 & 0 & 11 & 84 & 12 & 185 \\
$\mathbf{2 0 1 6}$ & 30 & 0 & 52 & 1 & 14 & 44 & 11 & 152 \\
$\mathbf{2 0 1 7}$ & 36 & 0 & 82 & 5 & 31 & 69 & 45 & 268 \\
$\mathbf{2 0 1 8}$ & 34 & 38 & 87 & 1 & 47 & 103 & 36 & 346 \\
$\mathbf{2 0 1 9}$ & 19 & 4 & 89 & 21 & 53 & 108 & 61 & 355 \\
\hline
\end{tabular}

Dari data di atas menunjukan jumlah bencana dari tahun ke tahun mengalami perubahan yang cukup signifikan. Hal tersebut terlihat dari jumlah keseluruhan bencana tiap tahun kecenderungan mengalami kenaikan. Kenaikan ini terlihat di tahun 2016 sampai 2019 dimana kebakaran menjadi jumlah kenaikan yang sangat tinggi.

Dari tabel 1, data bencana alam pada tahun 2020 akan dipakai sebagai uji validasi. Data tersebut ditampilkan pada tabel 3 dibawah ini.

Tabel 3. Data testing

\begin{tabular}{ccccccccc}
\hline Tahun & B & RB & TL & PB & RR & K & PT & JUMLAH \\
\hline $\mathbf{2 0 2 0}$ & 21 & 0 & 124 & 4 & 22 & 25 & 11 & 207 \\
\hline
\end{tabular}

Data training yang telah dijumlahkan, kemudian dihitung nilai probabilitasnya dengan algoritma markov chains. Adapun tahapannya adalah sebagai berikut:

1. Prediksi dengan Algoritma Markov Chains

Prediksi merupakan suatu metode yang mempelajari sifat-sifat suat variable pada masa sekarang yang di dasarkan sifat-sifatnya di masa lalu dalam usaha menaksir sifat-sifat variable yang sama di masa yang akan datang. Adapun langkah-langkah yang digunakan dalam penelitian ini adalah sebagai berikut:

a. Melakukan pengambilan data sekunder

Data sekunder yaitu menampilkan keseluruhan data bencana alam terekap pada BPBD Kota Semarang yang terpublish.

b. Menghitung peluang atau persentase masing-masing bencana setiap tahun

Nilai peluang pada algoritma markov chains terhitung sesuai dengan rumus $K t_{(j)}=P \times$ $K t_{(j-1)}$. Matrik peluang yang di hasilkan dari data training terlihat pada tabel berikut di bawah ini:

Tabel 4. Matrik peluang Markov Chains

\begin{tabular}{ccccccccc}
\hline Tahun & B & RB & TL & PB & RR & K & PT & JUMLAH \\
\hline $\mathbf{2 0 1 3}$ & 0,35 & 0,00 & 0,22 & 0,03 & 0,02 & 0,30 & 0,08 & $\mathbf{1 , 0 0}$ \\
$\mathbf{2 0 1 4}$ & 0,11 & 0,00 & 0,52 & 0,02 & 0,08 & 0,24 & 0,03 & $\mathbf{1 , 0 0}$ \\
$\mathbf{2 0 1 5}$ & 0,26 & 0,00 & 0,16 & 0,00 & 0,06 & 0,45 & 0,06 & $\mathbf{1 , 0 0}$ \\
$\mathbf{2 0 1 6}$ & 0,20 & 0,00 & 0,34 & 0,01 & 0,09 & 0,29 & 0,07 & $\mathbf{1 , 0 0}$ \\
$\mathbf{2 0 1 7}$ & 0,13 & 0,00 & 0,31 & 0,02 & 0,12 & 0,26 & 0,17 & $\mathbf{1 , 0 0}$ \\
$\mathbf{2 0 1 8}$ & 0,10 & 0,11 & 0,25 & 0,00 & 0,14 & 0,30 & 0,10 & $\mathbf{1 , 0 0}$ \\
$\mathbf{2 0 1 9}$ & 0,05 & 0,01 & 0,25 & 0,06 & 0,15 & 0,30 & 0,17 & $\mathbf{1 , 0 0}$ \\
\hline
\end{tabular}

c. Mengalikan matriks state bencana dengan matriks data bencana

Berdasarkan perhitungan peluang yang ada pada tabel 4 maka di tuliskan dalam matrik sebagai berikut: 


$$
\rho=\left[\begin{array}{lllllll}
0,35 & 0,00 & 0,22 & 0,03 & 0,02 & 0,30 & 0,08 \\
0,11 & 0,00 & 0,52 & 0,02 & 0,08 & 0,24 & 0,03 \\
0,26 & 0,00 & 0,16 & 0,00 & 0,06 & 0,45 & 0,06 \\
0,20 & 0,00 & 0,34 & 0,01 & 0,09 & 0,29 & 0,07 \\
0,13 & 0,00 & 0,31 & 0,02 & 0,12 & 0,26 & 0,17 \\
0,10 & 0,11 & 0,25 & 0,00 & 0,14 & 0,30 & 0,10 \\
0,05 & 0,01 & 0,25 & 0,06 & 0,15 & 0,30 & 0,17
\end{array}\right]
$$

1) Mengalikan state bencana dengan matriks data bencana alam

State bencana adalah jenis bencana yang dilambangkan dengan biner 0 atau 1 . Dalam hal ini isi state bencana untuk prediksi kota semarang ada 7, yaitu: banjir, rob banjir, tanah longsor, puting beliung, rumah roboh, kebakaran dan pohon tumbang. Maka jika dilambangkan dalam bentuk matrik dengan huruf $[B, R B, T L, P B, R R, K, P T]$ dan jika dengan bilangan biner seperti berikut $[0,0,0,0,0,0,0]$.

2) Kemungkinan bencana di tahun 2020

Kemungkinan bencana di tahun 2020 dapat di hitung dengan cara sebagai berikut:

$$
\pi(1)=\pi(0) \rho
$$

$$
\begin{aligned}
& \pi(1)=\left[\begin{array}{lllllll}
1 & 0 & 0 & 0 & 0 & 0 & 0
\end{array}\right] \times\left[\begin{array}{lllllll}
0,35 & 0,00 & 0,22 & 0,03 & 0,02 & 0,30 & 0,08 \\
0,11 & 0,00 & 0,52 & 0,02 & 0,08 & 0,24 & 0,03 \\
0,26 & 0,00 & 0,16 & 0,00 & 0,06 & 0,45 & 0,06 \\
0,20 & 0,00 & 0,34 & 0,01 & 0,09 & 0,29 & 0,07 \\
0,13 & 0,00 & 0,31 & 0,02 & 0,12 & 0,26 & 0,17 \\
0,10 & 0,11 & 0,25 & 0,00 & 0,14 & 0,30 & 0,10 \\
0,05 & 0,01 & 0,25 & 0,06 & 0,15 & 0,30 & 0,17
\end{array}\right] \\
& \pi(1)=\left[\begin{array}{lllllll}
0,35 & 0,00 & 0,22 & 0,03 & 0,02 & 0,30 & 0,08
\end{array}\right]
\end{aligned}
$$

Untuk membuat nilai probabilitas menjadi presentase, maka hasil dari $\pi(1)$ dikalikan dengan $100 \%$. Sehingga menjadi:

$\pi(1)=\left[\begin{array}{lllllll}35 \% & 0 \% & 22 \% & 3 \% & 2 \% & 30 \% & 8 \%\end{array}\right]$ Jadi kemungkinan bencana alam banjir di tahun 2020 adalah $35 \%$, rumah roboh 0\%, tanah longsor $22 \%$, puting beliung $3 \%$, rumah roboh $2 \%$, kebakaran $30 \%$ dan pohon tumbang $8 \%$.

3) Kemungkinan bencana di tahun 2021

bencana di tahun 2021 dapat dihitung dengan cara sebagai berikut:

$$
\pi(1)=\pi(0) \rho
$$

$\pi(1)=\left[\begin{array}{lllllll}0,35 & 0,00 & 0,22 & 0,03 & 0,02 & 0,30 & 0,08\end{array}\right] \times\left[\begin{array}{ccccccc}0,35 & 0,00 & 0,22 & 0,03 & 0,02 & 0,30 & 0,08 \\ 0,11 & 0,00 & 0,52 & 0,02 & 0,08 & 0,24 & 0,03 \\ 0,26 & 0,00 & 0,16 & 0,00 & 0,06 & 0,45 & 0,06 \\ 0,20 & 0,00 & 0,34 & 0,01 & 0,09 & 0,29 & 0,07 \\ 0,13 & 0,00 & 0,31 & 0,02 & 0,12 & 0,26 & 0,17 \\ 0,10 & 0,11 & 0,25 & 0,00 & 0,14 & 0,30 & 0,10 \\ 0,05 & 0,01 & 0,25 & 0,06 & 0,15 & 0,30 & 0,17\end{array}\right]$

$\pi(1)=\left[\begin{array}{lllllll}0,22 & 0,03 & 0,22 & 0,02 & 0,08 & 0,33 & 0,09\end{array}\right]$

Untuk membuat nilai probabilitas menjadi presentase, maka hasil dari $\pi(1)$ dikalikan dengan $100 \%$. Sehingga menjadi:

$\pi(1)=\left[\begin{array}{lllllll}22 \% & 3 \% & 22 \% & 2 \% & 8 \% & 33 \% & 9 \%\end{array}\right]$ 
jadi kemungkinan bencana alam banjir di tahun 2021 adalah $22 \%$, rumah roboh 3\%, tanah longsor $22 \%$, puting beliung $2 \%$, rumah roboh $8 \%$, kebakaran $33 \%$ dan pohon tumbang $9 \%$.

Berdasarkan dari hasil perhitungan probabilitas dengan metode markov chains pada data bencana alam di Kota Semarang. Di tahun 2020 dan 2021 terjadi perubahan prosentase kemungkinan terjadinya bencana lama mulai banjir, rob banjir, tanah longsor, puting beliung, rumah roboh, kebakaran dan pohon tumbang. Prediksi tersebut dapat dilihat pada tabel di bawah ini.

Tabel 5. Hasil prediksi nilai probabilitas markov chains tahun 2020 dan 2021

\begin{tabular}{cccccccc}
\hline Tahun & B & RB & TL & PB & RR & K & PT \\
\hline $\mathbf{2 0 2 0}$ & 0,35 & 0,00 & 0,22 & 0,03 & 0,02 & 0,30 & 0,08 \\
$\mathbf{2 0 2 1}$ & 0,22 & 0,03 & 0,22 & 0,02 & 0,08 & 0,33 & 0,09 \\
\hline
\end{tabular}

Sedangkan jika di lakukan perhitungan nilai presentase prediksi bencana alam di tahun 2020 dan 2021 seperti tabel dibawah ini.

Tabel 6. Hasil prediksi nilai probabilitas markov chains tahun 2020 dan 2021

\begin{tabular}{cccccccc}
\hline Tahun & B & RB & TL & PB & RR & K & PT \\
\hline $\mathbf{2 0 2 0}$ & $35 \%$ & $0 \%$ & $22 \%$ & $3 \%$ & $2 \%$ & $30 \%$ & $8 \%$ \\
$\mathbf{2 0 2 1}$ & $22 \%$ & $3 \%$ & $22 \%$ & $2 \%$ & $8 \%$ & $33 \%$ & $9 \%$ \\
\hline
\end{tabular}

Tahap akhir dari penelitian ini adalah menentukan nilai validasi terhadap prediksi tahun 2020 dengan data bencana di tahun 2020. Adapun hasil validasi tercantum dalah tabel 7 di bawah ini:

Tabel 7. Nilai validasi kejadian bencana di tahun 2020

\begin{tabular}{cccccccc}
\hline Kejadian & B & RB & TL & PB & RR & K & PT \\
\hline Prediksi Th 2020 & 0,35 & 0 & 0,22 & 0,03 & 0,2 & 0,3 & 0,08 \\
Bencana Th 2020 & 21 & 0 & 124 & 4 & 22 & 25 & 11 \\
Prosentase Bencana Th 2020 & 0,10 & 0,00 & 0,60 & 0,02 & 0,11 & 0,12 & 0,05 \\
\hline
\end{tabular}

Hasil validasi terlihat bahwa nilai prediksi dengan kondisi data testing memiliki perbedaan yang cukup tinggi. Hal tersebut dapat terlihat dari angka prediksi Banjir (B) di tahun 2020 sebesar 0,35 sedangkan kenyataan di data bencana 2020 hanya bernilai 0,10 . Ini juga terjadi pada Tanah Longsor (TL) dalam prediksi bernilai 0,22 sedangkan pada data bencana mencapai 0,60 dan perbedaan terebut terjadi juga pada Putting Beliung (PB), Rumah Roboh (RR), Kebakaran (K) serta Pohon Tumbang (PT). Jika dibuat grafik maka akan terlihat pada gambar di bawah ini.

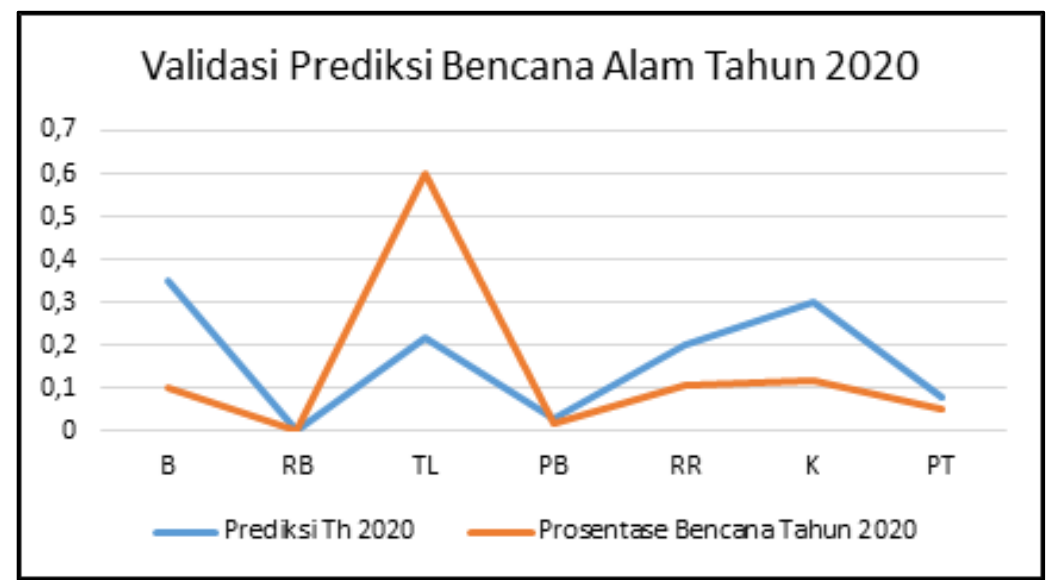

Gambar 3. Grafik validasi prediksi bencana alam tahun 2020 


\section{KESIMPULAN}

Berdasarkan hasil penelitian dan penghitungan prediksi dengan nilai probabilitas pada metode Markov Chains terhadap nilai presentase kemungkinan prediksi bencana alam di Kota Semarang pada tahun 2020 dan 2021, maka dapat disimpulkan bahwa nilai prediksi di tahun 2020 adalah banjir $35 \%$, rumah roboh $0 \%$, tanah longsor $22 \%$, puting beliung $3 \%$, rumah roboh $2 \%$, kebakaran 30\% dan pohon tumbang 8\%. Sedangkan nilai prediksi di tahun 2021 adalah banjir 22 $\%$, rumah roboh $3 \%$, tanah longsor $22 \%$, puting beliung $2 \%$, rumah roboh $8 \%$, kebakaran $33 \%$ dan pohon tumbang $9 \%$. Sedangkan nilai validasi yang didapatkan adalah terjadi perbedaan $17.87 \%$ dari nilai prediksi dengan kejadian bencana di tahun 2020 .

\section{DAFTAR PUSTAKA}

[1] M. I. Ramadhan and P. Prihandoko, "Penerapan Data Mining Untuk Analisis Data Bencana Milik BNPB Menggunakan Algoritma K-Means dan Linear Regression," J. Ilm. Inform. Komput., vol. 22, no. 1, pp. 57-65, 2019.

[2] Badan Penanggulangan Bencana Daerah Kota Semarang, "Data Bencana Alam di Kota Semarang Th. 2021," Semarang, 2021.

[3] F. A. Kurniawan, "Aplikasi Markov Chain untuk Memprediksi Tekanan Darah," InComTech J. Telekomun. dan Komput., vol. 8, no. 2, pp. 103-120, 2018, doi: 10.22441/incomtech.v8i2.4087.

[4] S. Nawangsari, F. M. Iklima, and E. P. Wbowo, "Konsep Markov Chains untuk Menyelesaikan Prediksi Bencana Alam di Wilayah Indonesia Dengan Studi Kasus Kotamadya Jakarta Utara,” J. Skripsi Progr. Stud. Sist. Inf., 2008.

[5] M. Mustakim, I. Kamila, and A. Ramadhan, "Implementasi Algoritma Markov Chains untuk Prediksi Kejadian Bencana Alam di Provinsi Riau," in Seminar Nasional Teknologi Informasi Komunikasi dan Industri, 2018, pp. 151-157.

[6] P. M. Melati and M. T. Jatipaningrum, "Prediksi Bencana Alam Di Wilayah Kabupaten Wonogiri Dengan Konsep Markov Chains," J. Stat. Ind. dan Komputasi, vol. 3, no. 01, pp. 63-70, 2018.

[7] M. G. Sadewo, A. Eriza, A. P. Windarto, and D. Hartama, "Algoritma K-Means Dalam Mengelompokkan Desa / Kelurahan Menurut Keberadaan Keluarga Pengguna Listrik dan Sumber Penerangan Jalan Utama Berdasarkan Provinsi," in Seminar Nasional Teknologi Komputer \& Sains (SAINTEKS), 2019, pp. 754-761.

[8] E. Prasetyo, Data Mining: Mengolah Data Menjadi Informasi Menggunakan Matlab. Yogyakarta: Andi, 2014.

[9] M. G. Sadewo, A. P. Windarto, and A. Wanto, "Penerapan Algoritma Clustering Dalam Mengelompokkan Banyaknya Desa/Kelurahan Menurut Upaya Antisipasi/ Mitigasi Bencana Alam Menurut Provinsi Dengan K-Means," KOMIK (Konferensi Nas. Teknol. Inf. dan Komputer), vol. 2, no. 1, pp. 311-319, 2018, doi: 10.30865/komik.v2i1.943.

[10] Suyanto, Data Mining Untuk Klasifikasi dan Klustering Data. Bandung: Informatika, 2019.

\section{Biodata Penulis}

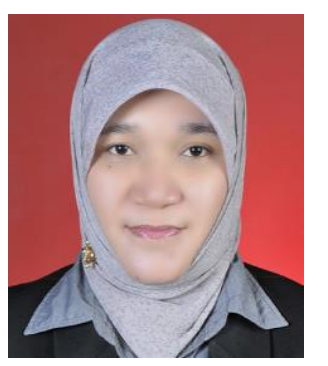

Nurtriana Hidayati lahir di Rembang, Jawa Tengah pada 22 Desember 1983 adalah seorang dosen sebuah perguruan tinggi swasta di kota Semarang, Jawa Tengah dengan bernama Universitas Semarang pada program studi S1 Sistem Informasi yang bernaung pada jurusan Teknologi Informasi dalam Fakultas Teknologi Informasi dan Komunikasi (FTIK). Sejak 2010 sudah selama 10 tahun ini mengampu pada bidang ilmu sesuai dengan pendidikan terakhir S2 pada Megister Sistem Informasi Universitas Diponegoro (UNDIP) dengan gelar M.Kom. Sistem Informasi memiliki ruang lingkup ilmu yang sangat penting sehingga selain mengajar pada 
program studi sistem informasi juga mengampu pada program studi S1 Teknik Informastika. Untuk menciptakan lulusan mahasiswa jurusan TI saya mengajarkan beberapa matakuliah diantaranya analisa dan perancangan sistem informasi, basis data, data mining dan rekayasa perangkat lunak.

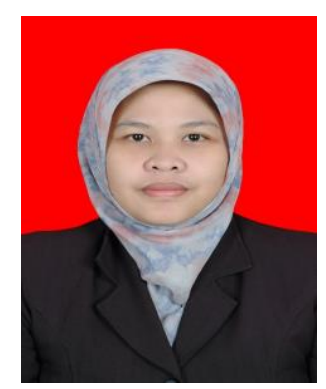

Prind Triajeng Pungkasanti, M.Kom, lahir di Medan 27 April 1983. Penulis bekerja di Universitas Semarang pada Program Studi Sistem Informasi. Beberapa matakuliah yang diampu penulis diantaranya sistem pendukung keputusan, basis data, analisa sistem.Penulis memperoleh gelar sarjana Sistem Informasi pada tahun 2006 di Unisbank Semarang. Kemudian penulis melanjutkan studi di bidang Sistem Informasi Universitas Diponegoro Semarang dan memperoleh gelar di tahun 2009. Selain aktif sebagai pengajar, penulis juga aktif melakukan penelitian.

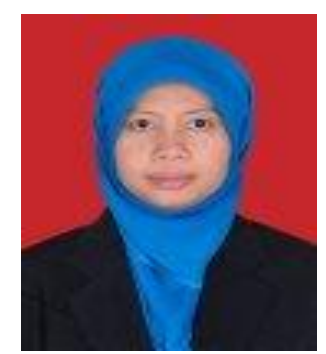

Nur Wakhidah lahir di Semarang pada tanggal 26 April 1979. Penulis sekarang bekerja sebagai pengajar di Jurusan Teknologi Informasi Universitas Semarang. Beberapa matakuliah yang diampu berada pada rumpun sistem cerdas, seperti kecerdasan buatan dan pengolahan citra. Gelar sarjana Teknik Informatika diraih pada tahun 2002 di Universitas Dian Nuswantoro Semarang. Kemudian penulis melanjutkan studi di Universitas GadjahMada dan menyelesaikan studi pada tahun 2010. Saat ini penulis selain aktif mengajar dan meneliti, penulis juga aktif sebagai reviewer di LPPM Universitas Semararang. 